\title{
Clostridium difficile infection in Polish pediatric outpatients with inflammatory bowel disease
}

\author{
D. Wultańska • A. Banaszkiewicz • A. Radzikowski • \\ P. Obuch-Woszczatyński • G. Młynarczyk • \\ J. S. Brazier • H. Pituch • A. van Belkum
}

Received: 11 March 2010 / Accepted: 29 May 2010 / Published online: 26 June 2010

(C) The Author(s) 2010. This article is published with open access at Springerlink.com

\begin{abstract}
The prevalence of Clostridium difficile infection (CDI) in pediatric patients with inflammatory bowel disease (IBD) is still not sufficiently recognized. We assessed the prevalence of $\mathrm{CDI}$ and recurrences in outpatients with IBD. In addition, the influence of IBD therapy on CDI and antimicrobial susceptibility of the potentially causative $C$. difficile strains was assessed. This was a prospective, single-center, observational study. All specimens were obtained between January 2005 and January 2007 from the IBD outpatient service and
\end{abstract}

D. Wultańska • P. Obuch-Woszczatyński • G. Młynarczyk •

H. Pituch

Department of Medical Microbiology,

Medical University of Warsaw,

Warsaw, Poland

A. Banaszkiewicz $\cdot$ A. Radzikowski

Pediatric Gastroenterology and Nutrition,

Medical University of Warsaw,

Warsaw, Poland

J. S. Brazier

Anaerobe Reference Laboratory,

National Public Health Service Microbiology Cardiff,

University Hospital of Wales,

Cardiff, UK

A. van Belkum

Department of Medical Microbiology and Infectious Diseases,

Erasmus University Medical Center Rotterdam,

Rotterdam, The Netherlands

H. Pituch $(\bowtie)$

Department of Medical Microbiology,

Medical University of Warsaw,

Chałubiński Street,

02-004 Warsaw, Poland

e-mail: hanna.pituch@wum.edu.pl screened for $C$. difficile and its toxins. $C$. difficile isolates were genotyped by PCR ribotyping. Diagnosis of Crohn's disease (CD) and ulcerative colitis (UC) was based on Porto criteria. Severity of disease was assessed using the Hyams scale (for Crohn's disease) and the Truelove-Witts scale (for ulcerative colitis). One hundred and forty-three fecal samples from 58 pediatric IBD patients $(21$ with Crohn's disease and 37 with ulcerative colitis) were screened. The risk of $C$. difficile infection was $60 \%$ and was independent of disease type (CD or UC) $(\chi 2=2.5821$, $\mathrm{df}=3, p=0.4606)$. About $17 \%$ of pediatric IBD patients experienced a recurrence of CDI. All $C$. difficile strains were susceptible to metronidazole, vancomycin and rifampin. A high prevalence of $C$. difficile infection and recurrences in pediatric outpatients with IBD was observed, independent of disease type. There was no significant correlation between $C$. difficile infection and IBD therapy. PCR ribotyping revealed C. difficile re-infection and relapses during episodes of IBD in pediatric outpatients.

\section{Introduction}

Clostridium difficile ( $C$. difficile) strains cause severe diarrhea and colitis in both adults and children [1, 2]. Clinically important $C$. difficile strains usually produce two toxins: toxin A (TcdA) - an enterotoxin - and toxin B (TcdB) - a cytotoxin. These toxins are the main virulence factors of $C$. difficile, responsible for symptoms of diarrhea and inflammation [3,4]. The epidemiology of $C$. difficile infection (CDI) has changed during the past decade. Traditional risk factors for $C$. difficile-associated disease are use of broad-spectrum antibiotic, chemotherapy, age over 65 years, and long-term hospitalization [5]. It was recently demonstrated that the use of immunomodulators 
and the presence of inflammatory bowel diseases (IBD) are important risk factors for the development of CDI [5-7].

The two major types of IBD are ulcerative colitis (UC) and Crohn's disease (CD). Patients with IBD are often hospitalized with worsening diarrhea, which is attributable to progression of their underlying disease. Whether infection plays a role in this process is ill-defined. Potential risk factors for the acquisition of $C$. difficile infection in IBD patients include drugs used in medical treatment (e.g., sulfasalazine), which might alter the intestinal flora and promote colonization, altered immune status possibly related to therapeutic agents, nutritional status and frequent hospitalizations [8]. IBD patients with colonic involvement exhibited a significant association with development of $C$. difficile infection, with both Crohn's disease and ulcerative colitis [6].

Clostridium difficile infection may be difficult to distinguish from an IBD onset or relapse, given the similar symptoms of diarrhea, abdominal pain, and low-grade fever. In addition, CDI might be more commonly community-acquired than hospital-acquired $[6,7,9]$. The frequency of $C$. difficile infection in IBD pediatric patients has not been established precisely, but seemed to be higher than in adults [10].

The aim of the study was to determine the prevalence of C. difficile infection in pediatric outpatients with active and inactive (in remission) IBD. Also, this study determined whether diarrhea episodes were due to $C$. difficile reinfection or relapse. In addition, the influence of treatment on $C$. difficile infection and the antimicrobial susceptibility of $C$. difficile strains were assessed.

\section{Materials and methods}

\section{Patients and specimens}

This was a prospective, single-center, observational study. All specimens were submitted and processed immediately from the out-patients service of the Department of Pediatric Gastroenterology and Nutrition in Warsaw, Poland between January 2005 and January 2007. We collected data on patient age and gender, antibiotic treatment and hospitalization within the 3 months before the time of $C$. difficile diagnosis. All drugs used by patients were recorded. Diagnosis of Crohn's disease and ulcerative colitis was based on clinical signs and symptoms combined with endoscopic, histological, and radiological results, which were interpreted according to the Porto criteria [11]. We used the modified Truelove and Witts activity index for ulcerative colitis and pediatrically modified Hyams activity index (PCDAI) for Crohn's disease. Active disease was defined as symptomatic UC with a Truelove-Witts score greater than 4 points and symptomatic CD with a PCDAI score greater than 10 points. The Truelove-Witts activity score is partly based on the patient's symptoms (number of stools, presence of blood in the stool, fever), but also on laboratory data (hemoglobin level, ESR) and nutritional assessment. The Hyams activity score assesses patient's symptoms (abdominal pain, bowel habits, overall well-being), laboratory findings (ESR, hemoglobin level, albumin level), physical examination of abdomen, presence of perianal complications, extraintestinal manifestation, and nutritional assessment.

Clostridium difficile infection recurrences were defined on the basis of defecation frequency as perceived by the patient. Increases should at least last for two consecutive days and stools should become progressively looser or new signs of severe colitis should develop. Microbiological evidence of the presence of toxins of $C$. difficile and/or the actual presence of toxin-producing $C$. difficile strains after an initial CDI treatment response should be presented. The fecal samples from patients with an active or an inactive form of IBD were collected in sterile universal collectors and send to the diagnostic laboratory. Stools samples were investigated for enteropathogenic organisms such as toxigenic Escherichia coli, Salmonella spp., Shigella spp., rota- and adenoviruses (VIKIA ROTA ADENO KIT; bioMérieux, Marcy l'Etoile, France). Patients with IBD were treated with sulfasalazine or mesalazine, azathioprine, cyclosporine, steroids and infliximab according to accepted clinical protocols. Patients with $C$. difficile infection (TcdA/TcdB toxins and/or toxigenic strains detection) were treated with metronidazole for 10-14 days per one episode, which was the standard antimicrobial treatment protocol.

\section{Diagnosis of $C$. difficile infection}

Diagnosis of CDI was based on a positive stool enzyme immunoassay (EIA) and/or on the isolation of toxigenic $C$. difficile strains. Either or both of the $C$. difficile toxins $\mathrm{Tcd} A / \mathrm{TcdB}$ were detected in the fecal samples with an enzyme immunoassay $\left(C\right.$. difficile TOX A/B II ${ }^{\mathrm{TM}}$; TechLab, Blacksburg, VA, USA). All fecal samples were inoculated after enrichment (by using an alcohol-shock procedure) onto selective Columbia Agar supplemented with cycloserine-cefoxitin and amphotericin B (CCCA medium; bioMérieux, Marcy l'Etoile, France) for detection of $C$. difficile. Plates were incubated in an anaerobic chamber (Forma Scientific, Marietta, GA, USA) at $37^{\circ} \mathrm{C}$ for 2 days [12]. The isolates were identified as $C$. difficile by the characteristic morphology of colonies, the specific horse odor, the yellow-green fluorescence under UV light (365 nm), Gram staining results, and biochemical tests (API 20A; bioMérieux, Marcy l'Etoile, France). For the detection 
of $t c d A / t c d B$ and binary toxin genes $(c d t A$ and $c d t B)$ genes, PCR was performed as described previously [12].

\section{PCR ribotyping}

Clostridium difficile isolates were typed by the PCR ribotyping methods described earlier [12]. Banding patterns were compared with those of the library of PCR ribotypes at the ARL, Cardiff [13].

\section{Determination of antibiotic susceptibility}

Minimal inhibitory concentration (MICs) for metronidazole (MZ), vancomycin (VA), ciprofloxacin (CI), gatifloxacin (GA), moxifloxacin (MX), and rifampin (RI) were determined by E-test (AB Biodisc, Solna, Sweden) according to the manufacturer's instructions, as described previously [12]. According to the Clinical and Laboratory Standard Institute (CLSI) recommendations (formerly NCCLS), antibiotic resistance was defined as follows: $\mathrm{MIC} \geq 32 \mathrm{mg} / \mathrm{L}$ for metronidazole, $\mathrm{MIC} \geq 32 \mathrm{mg} / \mathrm{L}$ for vancomycin, $\mathrm{MIC} \geq$ $4 \mathrm{mg} / \mathrm{L}$ for ciprofloxacin, $\mathrm{MIC} \geq 4 \mathrm{mg} / \mathrm{L}$ for gatifloxacin and $\mathrm{MIC} \geq 4 \mathrm{mg} / \mathrm{L}$ for moxifloxacin [14]. Rifampin resistance was defined as $\mathrm{MIC} \geq 32 \mathrm{mg} / \mathrm{L}$ in accordance with O'Connor et al. [15].

\section{Statistical analyses}

The Chi-squared test for independence was used to verify the hypothesis that infection $C$. difficile was independent of the type of illness. The gender proportions in groups were investigated by the Chi-squared test; for multiple comparisons LSD post hoc Fisher's test was used. The constancy of variance across the four patient groups was checked using Bartlett's test. We used Classical Multidimensional Scaling based on Hamming distance to identify common treatment schemes. We examined infection risk and explanatory variables using logistic regression. Yates' correction for continuity was used when needed.

\section{Ethical considerations}

The research presented in this manuscript was approved by the Ethics Committee on Clinical Investigation of the Medical University of Warsaw.

\section{Results}

One hundred forty-three fecal samples collected from 58 IBD pediatric patients were screened for $C$. difficile toxin TcdA/TcdB, and toxigenic $C$. difficile bacteria. Twenty-five females and 33 males, aged between 3 and 18 years (mean age 11.9 years), participated in this study. Of all patients in the IBD group 21 had Crohn's disease (CD) and 37 had ulcerative colitis (UC). Baseline characteristics of pediatric patients and stool samples are shown in Table 1. All stool samples were negative for enteropathogenic organisms such as toxigenic Escherichia coli, Salmonella spp., Shigella spp., enterotoxigenic $C$. perfringens, and rota- and adenoviruses (data not shown). None of the patients required hospitalization for more than 3 months before fecal sample collection.

Table 1 Therapeutic treatment, demographic and number of patients and faecal samples from paediatric outpatients in active (A) and inactive (I) IBD

\begin{tabular}{|c|c|c|c|c|c|c|c|c|c|c|c|}
\hline \multirow{2}{*}{$\begin{array}{l}\text { Demographic } \\
\text { of patients and } \\
\text { therapeutic } \\
\text { treatment }\end{array}$} & \multicolumn{2}{|c|}{$\mathrm{CD}^{\mathrm{a}}(\mathrm{n}=21)$} & \multicolumn{2}{|c|}{$\mathrm{UC}^{\mathrm{a}}(\mathrm{n}=37)$} & \multirow{2}{*}{$\begin{array}{l}\text { Number of faecal } \\
\text { samples from female } \\
\text { and male and } \\
\text { therapeutic treatment }\end{array}$} & \multicolumn{2}{|c|}{$\begin{array}{l}\text { Faecal samples } \\
(\mathrm{n}=143) \text { from } \\
\text { IBD patients }\end{array}$} & \multicolumn{2}{|c|}{$\mathrm{CD}^{\mathrm{a}}(\mathrm{n}=49)$} & \multicolumn{2}{|c|}{$\mathrm{UC}^{\mathrm{a}}(\mathrm{n}=94)$} \\
\hline & $\begin{array}{l}A^{b} \\
(n=11)\end{array}$ & $\begin{array}{l}\mathrm{I}^{\mathrm{b}} \\
(\mathrm{n}=10)\end{array}$ & $\begin{array}{l}A^{b} \\
(n=16)\end{array}$ & $\begin{array}{l}\mathrm{I}^{\mathrm{b}} \\
(\mathrm{n}=21)\end{array}$ & & $\begin{array}{l}\mathrm{A}^{\mathrm{c}} \\
(\mathrm{n}=62)\end{array}$ & $\begin{array}{l}\mathrm{I}^{\mathrm{c}} \\
(\mathrm{n}=81)\end{array}$ & $\begin{array}{l}A^{c} \\
(n=18)\end{array}$ & $\begin{array}{l}I^{\mathrm{c}} \\
(\mathrm{n}=31)\end{array}$ & $\begin{array}{l}\mathrm{A}^{\mathrm{c}} \\
(\mathrm{n}=44)\end{array}$ & $\begin{array}{l}\mathrm{I}^{\mathrm{c}} \\
(\mathrm{n}=50)\end{array}$ \\
\hline Male (n=33) & 6 & 8 & 10 & 9 & Male $(n=82)$ & 36 & 46 & 11 & 25 & 25 & 21 \\
\hline Female $(n=25)$ & 5 & 2 & 6 & 12 & Female $(n=61)$ & 26 & 35 & 7 & 6 & 19 & 29 \\
\hline Age $3-18$ yr & & & & & Age $3-18$ yr & & & & & & \\
\hline Sulfasalazine & 3 & 0 & 4 & 16 & Sulfasalazine & 23 & 43 & 3 & 3 & 20 & 40 \\
\hline Mesalazine & 6 & 7 & 13 & 6 & Mesalazine & 33 & 36 & 12 & 26 & 21 & 10 \\
\hline Azathioprine & 8 & 7 & 10 & 10 & Azathioprine & 38 & 53 & 14 & 30 & 24 & 23 \\
\hline Cyclosporine & 0 & 0 & 2 & 1 & Cyclosporine & 3 & 1 & 0 & 0 & 3 & 1 \\
\hline Steroids & 6 & 3 & 13 & 6 & Steroids & 41 & 22 & 7 & 5 & 34 & 17 \\
\hline Infliximab & 1 & 1 & 0 & 0 & Infliximab & 1 & 1 & 1 & 1 & 0 & 0 \\
\hline
\end{tabular}

Abbreviations: ${ }^{\text {a }} \mathrm{CD}$ or UC - patients with Crohn's disease or ulcerative colitis, respectively

${ }^{\mathrm{b}}$ number of patients (female or male) in active (A) or inactive (I) IBD.

${ }^{c}$ number of fecal samples in active (A) or inactive (I) IBD. 
Table 2 Summary of detection of TcdA/TcdB toxins and/or toxigenic C. difficile strains in specimens of pediatric outpatients with IBD and recurrences of CDI

\begin{tabular}{llllll}
\hline $\begin{array}{l}\text { Number of } \\
\text { faecal } \\
\text { samples }\end{array}$ & $\begin{array}{l}\text { Number (\%) of positive } \\
\text { faecal samples for CDI }\end{array}$ & $\begin{array}{l}\text { Number } \\
\text { of }_{\text {patients }}{ }^{\mathrm{d}}\end{array}$ & $\begin{array}{l}\text { Number (\%) of } \\
\text { positive patients for } \\
\text { CDI }^{\mathrm{c}}\end{array}$ & $\begin{array}{l}\text { Number of patients } \\
\text { with recurrences }^{\mathrm{e}}\end{array}$ & $\begin{array}{l}\text { Distribution of common genotypes } \\
\text { in patients with recurrences of CDI }\end{array}$ \\
\hline $\mathrm{IBD}^{\mathrm{b}} \mathrm{n}=143$ & $86 / 143(60 \%)$ & $\mathrm{IBD}^{\mathrm{b}} \mathrm{n}=58$ & $40 / 58(69 \%)$ & $10 / 58(17 \%)$ & 014 \\
$\mathrm{n}=62(\mathrm{~A})$ & $42 / 86(49 \%)$ & $\mathrm{n}=27(\mathrm{~A})$ & $18(66 \%)$ & $5 / 27(18 \%)$ & 014 \\
$\mathrm{n}=81(\mathrm{I})$ & $44 / 86(51 \%)$ & $\mathrm{n}=31(\mathrm{I})$ & $22(71 \%)$ & $5 / 31(16 \%)$ & $014 / 010$ \\
$\mathrm{CD}^{\mathrm{b}} \mathrm{n}=49$ & $29 / 49(59 \%)$ & $\mathrm{CD}^{\mathrm{b}} \mathrm{n}=21$ & $13(62 \%)$ & $3 / 21(14 \%)$ & 014 \\
$\mathrm{n}=18(\mathrm{~A})$ & $12 / 29(41 \%)$ & $\mathrm{n}=11(\mathrm{~A})$ & $7(64 \%)$ & $1 / 11(9 \%)$ & 014 \\
$\mathrm{n}=31(\mathrm{I})$ & $17 / 29(59 \%)$ & $\mathrm{n}=10(\mathrm{I})$ & $6(60 \%)$ & $2 / 10(20 \%)$ & $014 / 010$ \\
$\mathrm{UC} C^{\mathrm{b}} \mathrm{n}=94$ & $57 / 94(61 \%)$ & $\mathrm{UC} C^{\mathrm{b}} \mathrm{n}=37$ & $27(73 \%)$ & $7 / 37(20 \%)$ & 014 \\
$\mathrm{n}=44(\mathrm{~A})$ & $30 / 57(53 \%)$ & $\mathrm{n}=16(\mathrm{~A})$ & $12(75 \%)$ & $4 / 16(25 \%)$ & 014 \\
$\mathrm{n}=50(\mathrm{I})$ & $27 / 57(47 \%)$ & $\mathrm{n}=21(\mathrm{I})$ & $15(71 \%)$ & $3 / 21(14 \%)$ & 014 \\
\hline
\end{tabular}

Abbreviations: ${ }^{\mathrm{a}}$ number of fecal samples received from patients with IBD active (A) or inactive (I), ${ }^{\mathrm{b}}$ IBD -inflammatory bowel disease, CD-Crohn disease, UC-ulcerative colitis, ${ }^{\mathrm{c}} \mathrm{C}$. difficile toxins and/or toxigenic $C$. difficile strains, ${ }^{\mathrm{d}}$-number of patients with IBD (CD or UC) active (A) or inactive (I), ${ }^{\mathrm{f}}$ PCRribotype of $C$. difficile strains; ${ }^{\mathrm{e}}$ number of patients with recurrences with IBD (A) or (I); ${ }^{\mathrm{f}}$ PCR-ribotypes caused recurrences in patients with IBD (A) or (I)

Clostridium difficile toxins were identified in $60 \%$ of the stool samples (86 out of 143) and in $69 \%$ of the pediatric patients (40 out of 58) participating in this study. The risk of $C$. difficile infection was independent of disease type (Crohn's disease or ulcerative colitis; $\chi^{2}=2.5821, \mathrm{df}=3, p=$ 0.4606). TcdA/TcdB detection rates and $C$. difficile culture data are shown in Table 2. A highly significant relationship between the presence of $C$. difficile toxins and IBD, both active $(p<0.0001)$ and inactive $(p<0.0001)$, was observed. In addition, no significant correlation was found between $C$. difficile infection and IBD therapy, which included sulfasalazine $(p=0.1856)$, mesalazine $(p=0.129)$, azathioprine $(p=0.341)$, and steroids $(p=0.8255)$. Cyclosporine and infliximab were excluded from the statistical analysis because of their insignificant numbers.

From EIA-positive stool samples we cultured $18 C$. difficile strains. PCR-ribotyping identified five different ribotypes: three among the toxigenic $(014,018,046)$ and two among the non-toxigenic strains $(010,035)$. The most predominant ribotype was $014\left(\mathrm{~A}^{+} \mathrm{B}^{+} \mathrm{CDT}^{-}\right)$accounting for $50 \%$ of all strains. Two to seven clinical recurrences of C. difficile infection were observed during the study period among IBD patients and $17 \%$ of all 58 patients had recurrences (Table 2). Strains isolated during the first episode of $C$. difficile infection usually belonged to PCRribotype 014 , and strains from the re-infections belonged to different ribotypes (ribotype 018 or 046). Colonization of the gastrointestinal tract with non-toxigenic $C$. difficile strains (ribotype 010 or 035 ) was very frequent among the IBD patients.

All $C$. difficile strains were susceptible to metronidazole (MIC range $0.023-0.38 \mathrm{mg} / \mathrm{L}$ ), vancomycin (MIC range $0.25-1.5 \mathrm{mg} / \mathrm{L})$, rifampin $(\mathrm{MIC}=0.002 \mathrm{mg} / \mathrm{L}$ for all strains), moxifloxacin (MIC range $0.064-1.5 \mathrm{mg} / \mathrm{L}$ ) and gatifloxacin (MIC range $0.5-1.5 \mathrm{mg} / \mathrm{L}$ ), but were resistant to ciprofloxacin (MIC $\geq 32 \mathrm{mg} / \mathrm{L}$ ).

\section{Discussion}

In our study, the prevalence of $C$. difficile infection in pediatric outpatients with IBD was assessed as being $69 \%$. This is clearly higher than reported in the only previously published pediatric study (27.8\%) [10] or among adults with IBD $(4.2-5.8 \%)[6,7]$. Several factors could explain our results. First, the majority of our children were outpatients and previous studies showed that the majority of IBD patients contract $C$. difficile infections outside the hospital $[6,7]$. A second possible reason is the way we controlled our patients: a fecal sample for toxin detection was collected during every follow-up visit, which are regularly arranged even in the absence of aggravation. Finally, the incidence of $C$. difficile infection in Polish pediatric IBD patients is unknown, but it could simply be higher than in Western Europe or the United States.

Large population-based studies have demonstrated that CDI is more common in ulcerative colitis (UC) than Crohn's disease $(\mathrm{CD})[6,7]$. Our data showed that no specific type of IBD in our pediatric outpatients predisposed to $C$. difficile infection; the risk of $C$. difficile infection was the same in both UC and CD. This can be explained by the fact that the majority of our $\mathrm{CD}$ patients had colonic disease. IBD patients with colonic involvement exhibited a significant association with the development of $C$. difficile infection [16]. However, the lack of a comparator population (patients without IBD) limits the strength of the study. 
We detected no significant correlation between the risk of $C$. difficile infection and IBD therapy, including antiinflammatory drugs (sulfasalazine, mesalazine) or immune-modulating drugs (azathioprine, systemic steroids). These findings confirmed results from the published pediatric study [10], but not those from adult studies, which had shown that immune modulators were risk factors for $C$. difficile infection in hospitalized IBD patients $[6,17]$. The impact of ongoing immune modulation on $C$. difficile infection in adult outpatients is as yet undefined.

Two, 3, 4, and 7 recurrences of $C$. difficile infection were observed during the study period in $1,4,4$, and 1 patients respectively. Recurrences of $C$. difficile infection among IBD patients are a serious problem, especially for patients with 3 or more episodes [18]. Issa et al. demonstrated that $59 \%$ of the patients with IBD had a clinical recurrence within 1 month of the initial resolution of symptoms using metronidazole or vancomycin [19]. Another 22\% had persistent symptoms with frequent relapses. The data regarding the recurrence rate of $C$. difficile in the adult IBD population are limited and there are no data at all for pediatric IBD patients [16]. Recurrences of $C$. difficile may be explained either by the endogenous persistence of a $C$. difficile strain (relapse) or by acquisition of a new strain from the environment (re-infection) [20]. We have shown both scenarios to be relevant. However, our data are limited because of small numbers of $C$. difficile isolates.

Two reports have previously shown that $38-56 \%$ of recurrent $C$. difficile infection were in fact due to reinfections [21, 22]. Barbut et al. showed that $48.4 \%$ of clinical recurrences among patients hospitalized in different clinical units in France were in fact re-infections with a different strain of $C$. difficile [20]. Our results point to frequent (re-)infection caused by one type of $C$. difficile (PCR-ribotype 014). Relapses followed each other more closely (less than 1 month between episodes) than reinfections. Metronidazole and oral vancomycin have been shown to be effective in the treatment of $C$. difficileassociated diseases, but symptomatic recurrences occur in $15-30 \%$ of cases [21-23].

Currently, there are no specific antibiotic regimens recommended for IBD patients suffering from CDI. Metronidazole is still considered the first-line therapy for C. difficile infection, so all of our patients were treated with metronidazole. In spite of reports that metronidazole treatment for $C$. difficile infection is effective in only $50 \%$ of patients [6], we did not observe resistance to metronidazole and vancomycin in pediatric $C$. difficile strains [24]. We observed that all strains isolated from pediatric IBD outpatients were susceptible to rifampin.

Fluoroquinolones are a mainstay of treatment in patients with IBD, particularly for management of suppurative complications such as abscesses in Crohn's disease [6]. Our findings confirmed that the resistance of $C$. difficile to ciprofloxacin was very frequent $[9,24,25]$. However, resistance to newer fluoroquinolones such as gatifloxacin and moxifloxacin was not observed among strains isolated from our patients with IBD.

\section{Conclusions}

We report a high prevalence of CDI in pediatric outpatients with inflammatory bowel disease, a clear risk of CDI in both ulcerative colitis and Crohn's disease. In addition, there was no significant correlation between $C$. difficile infection and IBD therapy, and PCR ribotyping revealed both $C$. difficile re-infection and relapses during episodes of IBD in pediatric outpatients.

Conflict of interest None. The authors alone are responsible for the content and writing of the paper.

Open Access This article is distributed under the terms of the Creative Commons Attribution Noncommercial License which permits any noncommercial use, distribution, and reproduction in any medium, provided the original author(s) and source are credited.

\section{References}

1. Brazier JS (1998) The epidemiology and typing of Clostridium difficile. J Antimicrob Chemother 41 [Suppl C]:47-57

2. Brook I (2005) Pseudomembranous colitis in children. J Gastroenterol Hepatol 20:182-186. doi:10.1111/j.1440-1746.2004.03466.x

3. Borriello SP (1998) Pathogenesis of Clostridium difficile infections. J Antimicrobiol Chemother 41 [Suppl C]:13-19

4. Voth DE, Ballard JD (2005) Clostridium difficile toxins: mechanism of action and role in disease. Clin Microbiol Rev 18:247263. doi:10.1128/CMR.18.2.247-263.2005

5. McFarland LV, Beneda HW, Clarridge JE, Raugi GJ (2007) Implications of the changing face of Clostridium difficile disease for health care practitioners. Am J Infect Control 35:237-253. doi:10.1016/j.ajic.2006.06.004

6. Issa M, Vijayapal A, Graham MB, Beaulieu DB, Otterson MF, Lundeen $\mathrm{S}$ et al (2007) Impact of Clostridium difficile on inflammatory bowel disease. Clin Gastroenterol Hepatol 5:345351. doi:10.1016/j.cgh.2006.12.028

7. Rodemann JF, Dubberke ER, Reske KA, da Seo H, Stone CD (2007) Incidence of Clostridium difficile infection in inflammatory bowel disease. Clin Gastroenterol Hepatol 5:339-344. doi:10.1016/j.cgh.2006.12.027

8. Freeman HJ (2008) Recent developments on the role of Clostridium difficile in inflammatory bowel disease. World $\mathrm{J}$ Gastroenterol 14:2794-2796. doi:10.3748/wjg.14.2794

9. Tremaine W (2007) Inflammatory bowel disease and Clostridium difficile-associated diarrhea: a growing problem. Clin Gastroenterol Hepatol 5:310-311. doi:10.1016/j.cgh.2006. 12.030 
10. Pascarella F, Martinelli M, Miele E, Del Pezzo M, Roscetto E, Staiano A (2009) Impact of Clostridium difficile infection on pediatric inflammatory bowel disease. J Pediatr 154:854-858. doi:10.1016/j.jpeds.2008.12.039

11. IBD Working Group of the European Society for Paediatric Gastroenterology, Hepatology and Nutrition (2005) Inflammatory bowel disease in children and adolescents: recommendations for diagnosis - the Porto criteria. J Pediatr Gastroenterol Nutr 41:1-7

12. Pituch H, Brazier J, Obuch-Woszczatyński P, Wultańska D, Meisel-Mikołajczyk F, Łuczak M (2006) Prevalence and association of PCR ribotypes of $C$. difficile isolated from symptomatic patients from Warsaw with macrolide-lincosamide-streptogramin B $\left(M_{\mathrm{BLS}}\right)$ type resistance. J Med Microbiol 55:207-213. doi:10.1099/jmm.046213-0

13. Stubbs SL, Brazier JS, O'Neill GL, Duerden BI (1999) PCR targeted to the 16S-23S rRNA gene intergenic spacer region of Clostridium difficile and construction of a library consisting of 116 different PCR ribotypes. J Clin Microbiol 37:461-463

14. Clinical and Laboratory Standards Institute (2006) Methods for antimicrobial susceptibility testing of anaerobic bacteria, approved standard M11-A6, 6th edn. CLSI, Wayne, PA

15. O'Connor JR, Galang MA, Sambol SP, Hecht DW, Vedantam G, Gerding DN, Johnson S (2008) Rifampin and rifaximin resistance in clinical isolates of Clostridium difficile. Antimicrob Agents Chemother 52:2813-2817. doi:10.1128/AAC.00342-08

16. Nguyen GC, Kaplan GG, Harris ML, Brant SR (2008) A national survey of the prevalence and impact of Clostridium difficile infection among hospitalized inflammatory bowel disease patients. Am J Gastroenterol 103:1443-1450. doi:10.1111/ j.1572-0241.2007.01780.x

17. Ben-Horin S, Margalit M, Bossuyt P, Maul J, Shapira Y, Bojic D et al (2009) Combination immunomodulator and antibiotic treatment in patients with inflammatory bowel disease and Clostridium difficile infection. Clin Gastroenterol Hepatol 7:981-987. doi:10.1016/j. cgh.2009.05.031

18. Grybowski JD (1991) Clostridium difficile in inflammatory bowel disease relapse. J Pediatr Gastroenterol Nutr 13:39-41

19. Issa M, Ananthakrishnan AN, Binion DG (2008) Clostridium difficile and inflammatory bowel disease. Inflamm Bowel Dis 14:1432-1442. doi:10.1002/ibd.20500

20. Barbut F, Richard A, Hamadi K, Chomette V, Burghoffer B, Petit JC (2000) Epidemiology of recurrences or reinfections of Clostridium difficile-associated diarrhea. J Clin Microbiol 38:2386-2388

21. O’Neill GL, Beaman MH, Riley TV (1991) Relapse versus reinfection with Clostridium difficile. Epidemiol Infect 107:627635

22. Johnson S, Adelmann A, Clabots CR, Peterson LR, Gerding DN (1989) Recurrences of Clostridium difficile diarrhea not caused by the original infecting organism. J Infect Dis 159:340-343

23. Wilcox MH, Fawley WN, Settle CD, Davidson A (1998) Recurrence of symptoms in Clostridium difficile infectionrelapse or reinfection? J Hosp Infect 38:93-100. doi:10.1016/ S0195-6701(98)90062-7

24. Wultańska D, Obuch-Woszczatyński P, Pituch H, Łuczak M (2007) [Survey of susceptibility of clinical Clostridium diffiicile strains isolated from patients hospitalised in different departments of paediatric hospital to antimicrobial agents] [in Polish]. Med Dośw Mikrobiol 59:161-168

25. Spigaglia P, Barbanti F, Mastrantonio P, Brazier JS, Barbut F, Delmée M (2008) Fluoroquinolone resistance in Clostridium difficile isolates from a prospective study of $C$. difficile infections in Europe. J Med Microbiol 57:784-789. doi:10.1099/ jmm.0.47738-0 